\title{
Noncovalent Interactions of Tiopronin-Protected Gold Nanoparticles with DNA: Two Methods to Quantify Free Energy of Binding
}

\author{
R. Prado-Gotor and E. Grueso \\ Department of Physical Chemistry, Faculty of Chemistry, University of Sevilla, C/Profesor García González S/N, 41012 Sevilla, Spain \\ Correspondence should be addressed to E. Grueso; elia@us.es
}

Received 28 August 2013; Accepted 10 November 2013; Published 22 January 2014

Academic Editors: L. Y. Chen, D. Dondi, P. Pietrzyk, and R. Schweiss

Copyright (c) 2014 R. Prado-Gotor and E. Grueso. This is an open access article distributed under the Creative Commons Attribution License, which permits unrestricted use, distribution, and reproduction in any medium, provided the original work is properly cited.

\begin{abstract}
The binding of gold nanoparticles capped with N-(2-mercaptopropionyl)glycine (Au@tiopronin) with double-stranded DNA has been investigated and quantified in terms of free energies by using two different approaches. The first approach follows the DNA conformational changes induced by gold nanoparticles using the CD technique. The second methodology consists in the use of pyrene-1-carboxaldehyde as a fluorescent probe. This second procedure implies the determination of the "true" free energy of binding of the probe with DNA, after corrections through solubility measurements. Working at different salt concentrations, the nonelectrostatic and electrostatic components of the binding free energy have been separated. The results obtained revealed that the binding is of nonelectrostatic character, fundamentally. The procedure used in this work could be extended to quantify the binding affinity of other AuNPs/DNA systems.
\end{abstract}

\section{Introduction}

In recent years, the studies of noncovalent interactions of DNA with ligands have received considerable attention caused by the huge number of applications being derived from these interactions. Among these applications, the development of new diagnostic and therapeutic agents $[1,2]$, the exploration of the possibilities of DNA as molecular conductor [3], the interest in gene transport [4], and the fabrication of biosensors stand out [5-7]. In our group, we have a consistent background on the analysis of ligandreceptor interactions and of the kinetic analysis of DNAcontaining systems $[8,9]$. We considered (i) thermodynamic aspects of ligand-receptor (DNA) binding [10, 11]; (ii) the binding kinetics, including the influences of salts and cosolvents on the kinetics $[12,13]$, and (iii) the effect of DNA on the reactivity of ligands [14-16]. For these purposes, we have conveniently used substitution inert transition metal complexes [14], organic compounds [10, 12], surfactants [11, 12], bile salts [16], and gold nanoparticles [13].

Among a variety of these ligands, intense current interest is focused on gold colloids (AuNPs) due to their chemical stability, high biocompatibility and excellent structural, and optical, magnetic, and catalytic properties [17]. In particular, water soluble metal nanoparticles have received considerable attention due to the potential benefits in the fields of biology and medicine [18-22]. Especially interesting are alkanethiolates as protective agents due to their advantages of stability, suspendability in different solvents, and facile characterization by standard analytical techniques [23]. Since successful therapy for curing cancer and others genetic diseases requires the transport of DNA in the cell by delivery vehicles, the effective complexation of the DNA is a subject of great interest [24]. Numerous biological and medical applications in this active area of research are based on the binding of the nanoparticle probe to a particular biological substrate. More recently, sensors consisting of metal nanoparticles functionalized with DNA have appeared in the literature. It has been shown that these particles show affinities to the ligands that are, at least, two orders of magnitude greater than other conventional sensors [25-27]. However, little progress has been made in understanding noncovalent interactions of gold nanoparticles with nucleic acids [28-31] and quantitative 
studies on the affinity of these systems are even more scarce $[29,32,33]$. In this sense, the scope of this work is to quantify the thermodynamic aspects of DNA-Au@tiopronin binding. We are also interested in knowing how the environment surrounding the colloidal gold-DNA system, specifically the presence of salt $(\mathrm{NaCl})$, affects the complex formation. The aim of this thermodynamic investigation carried out in conjunction with a complementary structural and spectroscopy study was to learn more about the factors that control the complexation of DNA with gold nanoparticles.

\section{Materials and Methods}

2.1. Chemicals and Reagents. All chemicals were Analytical R. Grade and were used without further purification. Hydrogen tetrachloroaurate(III) trihydrate and pyrene-1carboxaldehyde (1-PyCHO) were purchased from SigmaAldrich; N-(2-mercaptopropionyl)glycine from Fluka; $\mathrm{NaBH}_{4}$ from Lancaster; and $\mathrm{NaCl}$ from Merck. Calf thymus DNA was purchased from Pharmacia (average number of base pairs: 10000) and used without further purification because preliminary experiments showed that purification does not produce any changes in experiments' results. Polynucleotide concentrations were determined spectrophotometrically from the molar absorptivity (6600 $\mathrm{mol}^{-1} \mathrm{dm}^{3} \mathrm{~cm}^{-1}$ at $258 \mathrm{~nm}$ in order to have the DNA concentration in phosphate units) [34]. Solutions were prepared with deionized water, the conductivity being less than $10^{-6} \mathrm{~S} \mathrm{~m}^{-1}$. The temperature was maintained at $298.2 \pm 0.1$ in all experiments.

2.1.1. Synthesis of Gold Nanoparticles (Au@tiopronin). Au@tiopronin nanoparticles were prepared using the procedure of Templeton et al. [35]. One batch with hydrogen tetrachloroaurate(III) trihydrate (1 equiv) and $\mathrm{N}$-(2-mercaptopropionyl)glycine (tiopronin) (5.5 equiv) was codissolved in $35 \mathrm{~mL}$ of $6: 1 \mathrm{methanol} /$ acetic acid, resulting in a ruby red solution. Sodium borohydride ( 22 equiv) in $15 \mathrm{~mL}$ of $\mathrm{H}_{2} \mathrm{O}$ was subsequently added via rapid stirring. The resultant brown suspension was stirred for an additional $30 \mathrm{~min}$ after cooling, with the solvent being removed under vacuum at $4^{\circ} \mathrm{C}$. The crude sample was completely insoluble in methanol but reasonably soluble in water. It was purified by dialysis, in which the $\mathrm{pH}$ of the crude product dissolved in $20 \mathrm{~mL}$ of water (NANOpure) was adjusted to 1 by dropwise addition of concentrated hydrochloric acid. This solution was loaded into $15 \mathrm{~cm}$ segments of seamless cellulose ester dialysis membrane (Sigma, MWCO $=10.000$ ), placed in $4 \mathrm{~L}$ beakers of water, and stirred slowly being recharged with fresh water ca. every $10 \mathrm{~h}$ over the course of $72 \mathrm{~h}$. NMR spectra were used in order to see that the tiopronin was not free but bound to the gold. The dark brown Au@tiopronin solutions were collected from the dialysis tubes and were lyophilized. The product materials were found to be spectroscopically clean and produced a yield of $119 \mathrm{mg}$.

TEM analysis was carried out in a Philips CM 200 electron microscope working at $200 \mathrm{kV}$. Size distributions of the $\mathrm{Au}$ cores were measured from enlarged TEM image photographs for at least 200 individual cluster core images. A value of $1.4 \mathrm{~nm}$ was obtained for the diameter of the gold nanoparticle. Au@tiopronin nanoparticles were also characterized by visible absorption spectra and $\mathrm{C}, \mathrm{H}, \mathrm{N}$, and S microanalysis $(14.04 \% \mathrm{C} ; 2.25 \% \mathrm{H} ; 3.51 \% \mathrm{~N} ; 7.78 \%$ $\mathrm{S})$. According to these data and the results of the TEM, the relation between the number of $\mathrm{Au}$ atoms and tiopronin ligands was 119/105 [35].

All the experiments were carried out from solutions of gold nanoparticles prepared by weight.

2.2. UV-Vis Spectra. The spectra of the Au@tiopronin in the presence and in the absence of DNA were recorded with a Cary 500 spectrophotometer from $280 \mathrm{~nm}$ to $800 \mathrm{~nm}$. The UV-vis absorption spectra showed a slight detectable surface plasmon band (SPB) as a consequence of the small size of the clusters (see Figure 2(a)). Titration experiments were carried out at a fixed colloidal gold concentration, [AuNPs] $=1.58 \times$ $10^{-6} \mathrm{M}$, and in a DNA concentration range from $6.7 \times 10^{-6}$ to $9.6 \times 10^{-5} \mathrm{M}$.

2.3. Fluorescence Measurements. Fluorescence measurements were carried out in a spectrofluorimeter (Hitachi f-2500), interfaced to a PC for the reading and handling of the spectra. For the study with the fluorescence intercalator, pyrene-1-carboxaldehyde (1-PyCHO), intensity measurements were performed at $[1-\mathrm{PyCHO}]=5 \cdot 10^{-7} \mathrm{M}$. The excitation and emission wavelengths were $356 \mathrm{~nm}$ and $458 \mathrm{~nm}$, respectively. It was checked that the results were independent of the excitation wavelength, provided that this one was in the range from 300 to $425 \mathrm{~nm}$. DNA concentrations ranged from $10^{-5} \mathrm{M}$ to $10^{-3} \mathrm{M}$. The water used in the preparation of solutions contained ethanol 5\% (by weight). The presence of the alcohol was necessary in order to make the probe, pyren-1-carboxyaldehyde, soluble.

For AuNPs/DNA titrations, a fixed colloidal gold concentration of $[$ AuNPs $]=1.5 \times 10^{-6} \mathrm{M}$ was used, the DNA concentration varying from $10^{-5} \mathrm{M}$ to $7 \times 10^{-5} \mathrm{M}$. The excitation wavelength was $451 \mathrm{~nm}$ whereas the emission wavelength was $656 \mathrm{~nm}$. The validation of the Beer-Lambert law was checked in the range of $\left[\right.$ AuNPs] $=5 \times 10^{-8}-2.16 \times 10^{-6} \mathrm{M}$.

2.4. Circular Dichroism (CD) Spectra. Electronic CD spectra were recorded in a BioLogic MOS-450 spectropolarimeter. A standard quartz cell of $10 \mathrm{~mm}$ path length was used. The spectra were expressed in terms of molar ellipticity. Scans were taken from $220 \mathrm{~nm}$ to $310 \mathrm{~nm}$. For each spectrum, 510 runs were averaged with a 5 min equilibration before each scan. All the spectra were performed at a fixed concentration of $[\mathrm{DNA}]=10^{-4} \mathrm{M}$.

2.5. Scanning Electron Microscopy (SEM). Scanning electron microscopy (SEM) images were obtained by using a Hitachi S5200 field-emission microscope. For SEM characterization, a drop of DNA or DNA/AuNPs solution was spread on a stub; the solvent was removed and then used. The samples were examined without specific manipulation. 
2.6. Solubility Measurements. The solubilities of pyren-1carboxaldehyde in solutions containing gold nanoparticles were measured by agitating a generous excess of solid with the appropriate solution in a thermostated $(298.2 \mathrm{~K})$ vessel. After waiting a long time for undissolved solids to settle, an aliquot of the saturated solution was removed using a prethermostated pipette and the solution was diluted as necessary. Concentrations were measured spectrofluorimetrically in terms of previous calibration of the fluorescence of the pyren-1-carboxaldehyde at 5\% ethanol with respect to the probe concentration. AuNPs concentrations corresponding to solubility measurements are given in Table 2 .

\section{Results and Discussion}

Tiopronin-protected gold clusters are alkanethiolate nanoparticles in which the presence of a carboxylic and amino group of the tiopronin allows to modify the charge of the nanoparticle as a function of the $\mathrm{pH}$ of the medium. As a consequence, this nanosystem can be used positively or negatively charged. This colloid system also offers potential advantages due to the stability conferred by the attachment of thiol groups, high solubility in water, facile characterization, and functionalization. In this sense, the possibility of functionalizing the carboxylic group with small oligopeptides can be taken into account [36]. It is important to note that all experiments in this paper were carried out at $\mathrm{pH}=6$. According to the $\mathrm{pKa}$ value of the tiopronin bound to the gold cluster, $\mathrm{pKa} \approx 5.6$, Au@tiopronin nanoparticles are mostly neutral and hydrophilic $[13,35]$. Therefore, the binding of tiopronin nanoparticles can be expected to occur principally through the formation of stable hydrogen bonding between the hydrophilic groups of the tiopronin and the DNA bases [13], and the strength of this interaction could be modified as a function of the media $\mathrm{pH}$. In order to provide evidences of the interaction of tiopronin-protected gold nanoparticles with DNA, different techniques were employed.

It is known that small gold nanoparticles are able to emit fluorescence [37]. Increasing amount of DNA was added to a solution containing a fixed nanoparticle concentration ( $[$ AuNPs $]=1.5 \times 10^{-6} \mathrm{M}$ ) and the changes on the fluorescence spectra were measured. In order to know if the nanoparticle aggregates, the linearity of the Beer-Lambert law for solutions containing various nanoparticles concentrations was tested. The inset in Figure 1(a) shows that at low AuNPs concentrations $(<2.16 \mu \mathrm{M})$ the fluorescence intensity changes linearly with concentration, while at higher concentrations the Beer-Lambert law does not work, possibly due to a selfquenching effect produced by the Au@tiopronin. We must notice the importance of the small core size of the metal nanoparticle in relation to its luminescence properties. This feature is particularly of interest for water-soluble AuNPs having tiopronin thiolate monolayers, smaller than $2 \mathrm{~nm}$. T. Huang et al. have studied the emission from tioproninAuNPs with different core sizes (1.8, 2.2, 3.1, and 3.9 nm) [37]. They found that only for the smallest nanoparticles $(1.8 \mathrm{~nm}$ core size), luminescence was observed $\left(\lambda_{\mathrm{em}}=770 \mathrm{~nm}\right)$. The luminescence maximum shifts to lower energy with increasing core size $[38,39]$. In that sense, the results in
Figure 1(b) obtained for our $1.4 \mathrm{~nm}$ AuNPs $\left(\lambda_{\mathrm{em}}=656 \mathrm{~nm}\right)$ are in good agreement with the paper of Huang and Murray. On the other hand, as can be seen in Figure 1, the intensity of emission can be modified by the presence of DNA. In fact, an increase in the fluorescence emission at $656 \mathrm{~nm}$ was observed with increasing DNA concentration. Similar behaviour was observed for larger gold Au@tiopronin nanoparticles of $1.8 \mathrm{~nm}$ core size. However, one or two ethidium thiolate ligands are needed to be inserted into the Au@tiopronin/ethidium nanoparticles in order to confer better luminescent properties [29].

With regard to UV-vis technique, Figure 2(b) shows the changes of the surface plasmon band (SPB) of colloidal gold as increasing amounts of DNA were added to the solution. Despite the small size of the nanoparticle, the SPB is almost nondetectable; in Figure 2 it can be observed how spectra are modified upon the binding of DNA. Moreover, the isosbestic point about $308 \mathrm{~nm}$ gives support to the DNA/Au@tiopronin complex formation.

These two conventional spectroscopy techniques provide evidence of interaction. Unfortunately, due to the small changes registered on spectra as the titration occurs, these techniques are not appropriate to quantify the binding constant of the Au@tiopronin/DNA interaction. Alternatively, we found that the $\mathrm{CD}$ technique provides a convenient method to quantify this interaction. The determination of the free energy of binding, that is, the free energy for the DNA/AuNPs complex formation, has been carried out following two different approaches. The first one is based on the measurement of the changes of DNA molar ellipticity in the presence of AuNPs. The second approach is based on the use of a fluorescent probe, pyrene-1-carboxaldehyde. In both cases, the starting point has been a two-state model. DNAAuNPs interaction causes a conformational change in the DNA structure during the course of the binding, which can be followed by the circular dichroism technique (see Figure 3). As is known, the backbone conformation of DNA shows a $\mathrm{CD}$ spectrum characteristic of the right-handed $\mathrm{B}$ form in the UV region (220-320 nm). Structure alterations of the DNA caused by its interaction with ligands are reflected in changes in this intrinsic CD spectrum. In Figure 3, the CD spectrum of free DNA has a positive peak at $279 \mathrm{~nm}$ and a negative peak at $247 \mathrm{~nm}$ which corresponds to B-DNA form. These bands are caused by stacking interactions between the bases and the helical suprastructure of the polynucleotide that provide an asymmetric environment for the bases [40]. In the same figure, an example of CD titration in water can be observed which clearly demonstrates that the helical conformation is not maintained.

Upon the addition of the gold clusters to the DNA solution, the molar ellipticity decreases at approximately $279 \mathrm{~nm}$; meanwhile, it increases at approximately $247 \mathrm{~nm}$. These changes are coupled with a shift in the maximum wavelength of the positive band, as can be seen in Figure 3(a), indicating partial denaturation of double strand [41, 42].

Further information about what kind of DNA conformational changes being induced by Au@tiopronin nanoparticles has been obtained by means of the SEM technique. Typical images of CT-DNA in the absence (Figure 4(b)) and in the 


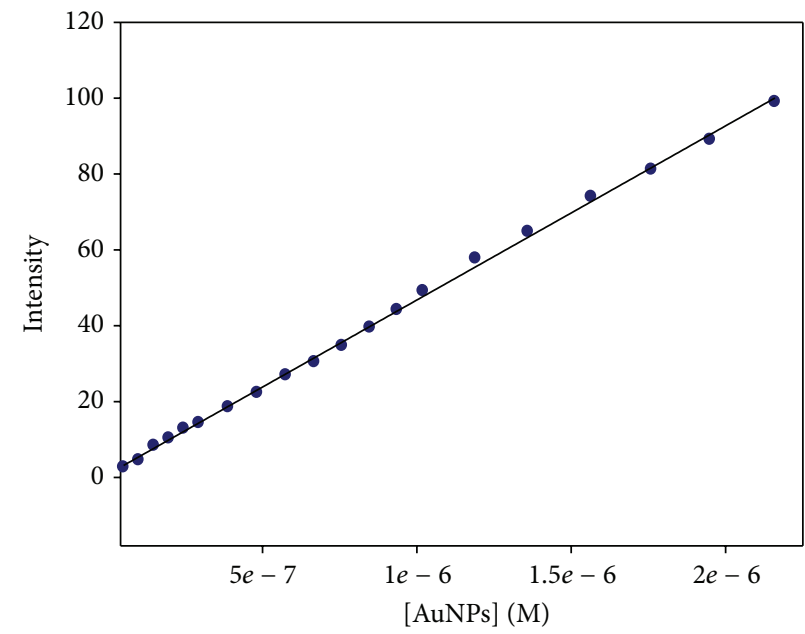

(a)

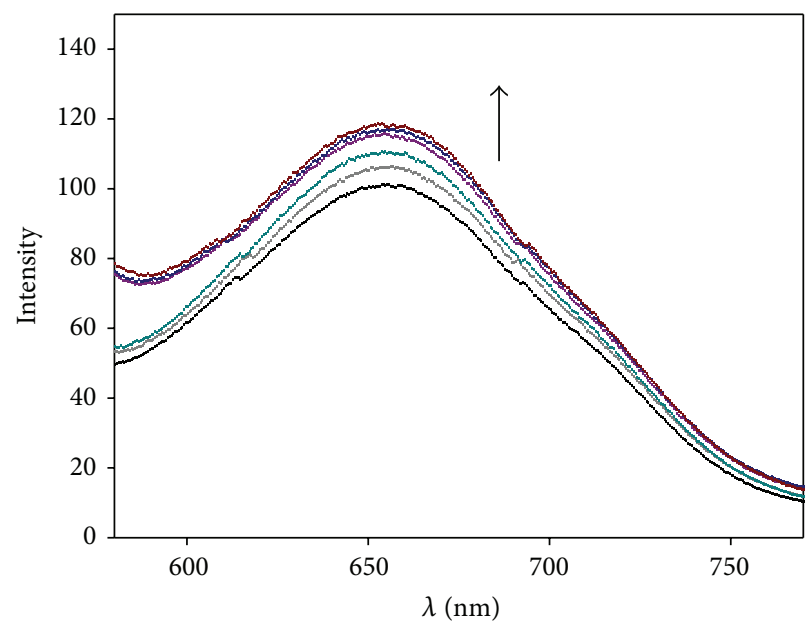

(b)

FIgURE 1: (a) Plot of fluorescence intensity at $656 \mathrm{~nm}$ of Au@tiopronin versus [AuNPs], in the absence of DNA. (b) Fluorescence spectra of AuNPs/DNA system recorded for increasing concentrations of DNA in $5 \%$ of ethanol. [AuNPs] $=1.5 \times 10^{-6} \mathrm{M}$; [DNA] $=0 \mathrm{M}$ (bottom); $[\mathrm{DNA}]=7 \times 10^{-5} \mathrm{M}$ (top).

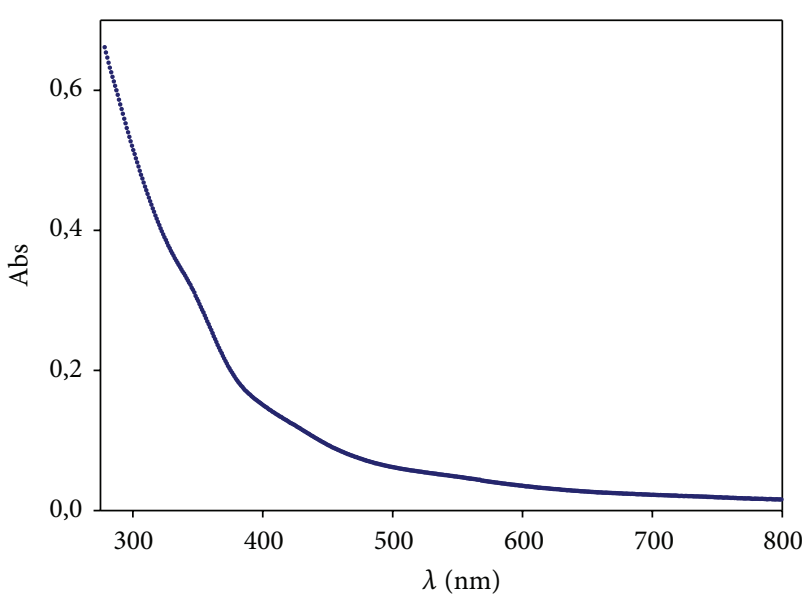

(a)

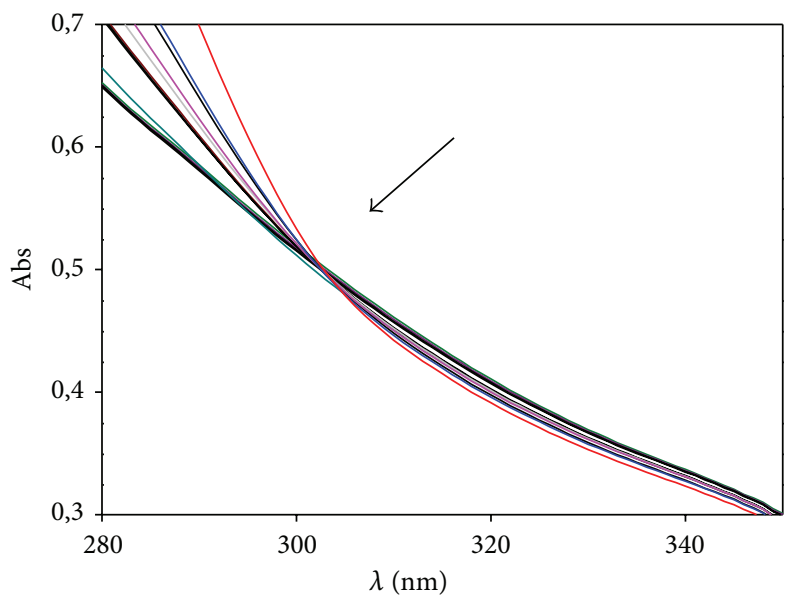

(b)

FIGURE 2: (a) Absorption spectrum of the Au@tiopronin. (b) Absorbance titration of AuNPs/DNA system recorded for increasing concentrations of DNA. [AuNPs $]=1.58 \times 10^{-6} \mathrm{M} ;[\mathrm{DNA}]=0 \mathrm{M}$ (top); [DNA] $=1 \times 10^{-4} \mathrm{M}$ (bottom).

presence (Figures 4(c) and 4(d)) of different amount of gold nanoparticles are given in Figure 4. It is clear from these images that gold nanoparticles induce a compaction of DNA molecules. It can also be seen in the figure that the degree of compaction increases with the concentration of nanoparticles.

Based on CD spectrum changes as Au@tiopronin nanoparticles were added to the DNA solution, it was possible to quantify the binding constant of the interaction.

According to a two-state model, changes on the DNA molar ellipticity should be the consequence of the distribution of the gold cluster in the bulk (water) and on the DNA surface (see Scheme 1).

According to this model, if the DNA and Au@tiopronin nanoparticles constitute a complex, at the equilibrium there will be two populations of DNA: free and bound to the nanoparticle:

$$
\begin{gathered}
{[\mathrm{DNA}]=\frac{1}{1+K^{\mathrm{DNA} / \mathrm{AuNPs}}[\mathrm{AuNPs}]}[\mathrm{DNA}]_{0},} \\
{[\mathrm{DNA} / \mathrm{AuNPs}]=\frac{K^{\mathrm{DNA} / \mathrm{AuNPs}}[\mathrm{AuNPs}]}{1+K^{\mathrm{DNA} / \mathrm{AuNPs}}[\mathrm{AuNPs}]}[\mathrm{DNA}]_{0},}
\end{gathered}
$$

where $[\mathrm{DNA}]_{0}$ is the total concentration of DNA, such that $[\mathrm{DNA}]_{0}=[\mathrm{DNA}]+[\mathrm{DNA} /$ AuNPs $]$. Accordingly, the observed molar ellipticity, $[\theta]$, would be given by

$$
[\theta]=\frac{[\theta]_{f}+[\theta]_{b} K^{\mathrm{DNA} / \mathrm{AuNPs}}[\text { AuNPs }]}{1+K^{\mathrm{DNA} / \mathrm{AuNPs}}[\mathrm{AuNPs}]} .
$$




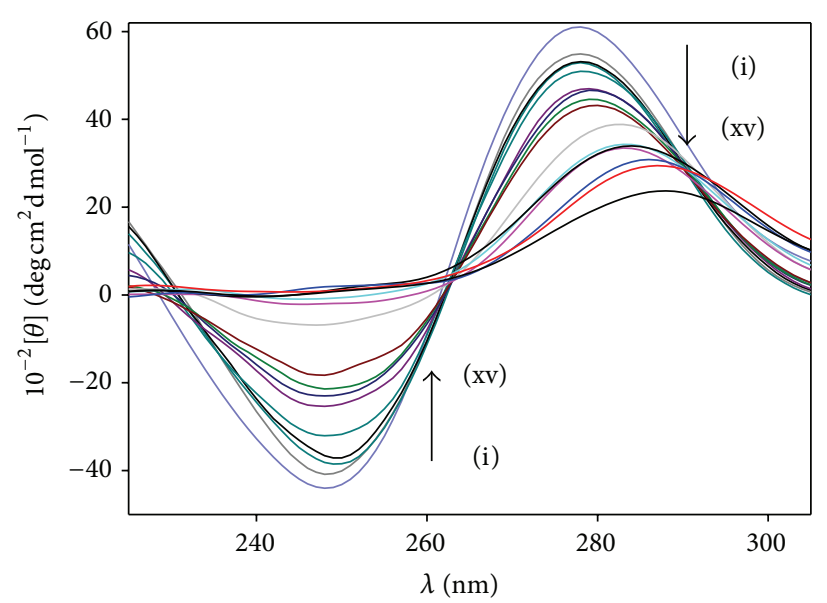

(a)

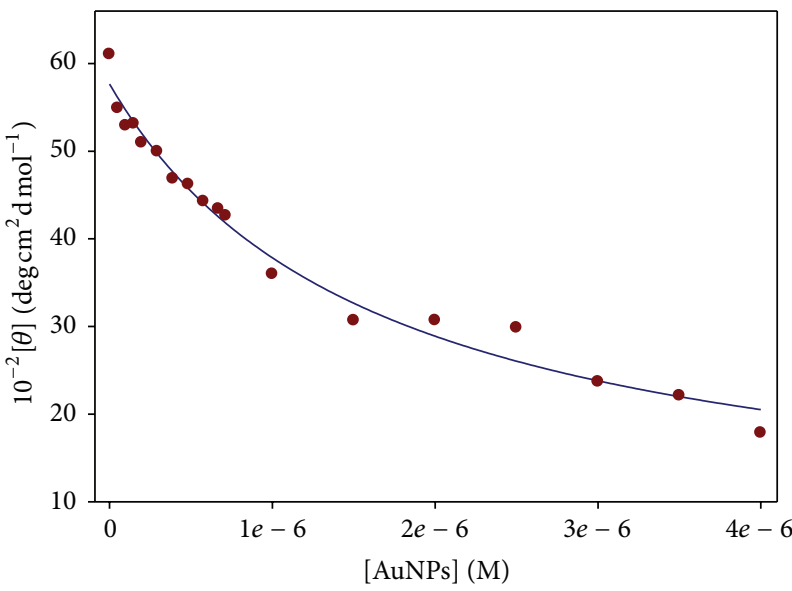

(b)

Figure 3: (a) CD titration of AuNPs with DNA in water. [DNA] $=1 \times 10^{-4} \mathrm{M}$. Curves from (i) to (xv) correspond to $0,0.15,0.29,0.39,0.58$, $0.71,1.00,1.50,2.00$, and $4.00 \mu \mathrm{M}$ of AuNPs. (b) Plot of the molar ellipticity experimental data versus AuNPs concentrations. Symbols $(\bullet)$ are experimental data and line is the best fit using (2).

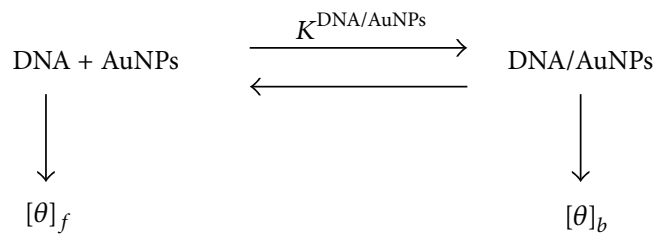

SCHEME 1

TABLE 1: Binding constants $\left(K^{\mathrm{DNA} / \mathrm{AuNPs}}\right)$ and the free energy of binding $\left(\Delta G^{\mathrm{DNA} / \mathrm{AuNPs}}\right)$ corresponding to DNA/AuNPs interaction at different $\mathrm{NaCl}$ concentrations.

\begin{tabular}{lcc}
\hline$[\mathrm{NaCl}] / \mathrm{M}$ & $10^{5} \mathrm{~K}^{\mathrm{DNA} / \mathrm{AuNPs}} / \mathrm{M}^{-1}$ & $\Delta G^{\mathrm{DNA} / \mathrm{AuNPs}} / \mathrm{kJmol}^{-1}$ \\
\hline 0.000 & 6.40 & -33.12 \\
0.002 & 6.34 & -33.10 \\
0.006 & 4.98 & -32.50 \\
0.010 & 3.88 & -31.88 \\
0.015 & 3.34 & -31.51 \\
\hline
\end{tabular}

Thus, $K^{\mathrm{DNA} / \mathrm{AuNPs}}$ can be obtained from the variations of $[\theta]_{279 \mathrm{~nm}}$ caused by the changes of [AuNPs]. Figure 3(b) gives these variations. Consequently, by fitting the experimental values of $[\theta]$ to $(2)$, a value of $K^{\text {DNA/AuNPs }}=6.4 \times 10^{5} \mathrm{M}^{-1}$ was obtained in water.

Similar experiments were carried out in the presence of different $\mathrm{NaCl}$ concentrations. The results (values of $\left.K^{\mathrm{DNA} / \mathrm{AuNPs}}\right)$ of these experiments are given in Table 1 .

As can be seen in this table, the binding of DNA with AuNPs is somewhat sensitive to the ionic strength. This fact could be indicative of a slight electrostatic character of the binding. Therefore, the free energy of binding can be written as the sum of two contributions: (i) an electrostaticpotential-independent contribution, $\Delta G_{\text {nel }}$ (nonelectrostatic or intrinsic), and (ii) an electrostatic-potential-dependent contribution, $\Delta G_{\mathrm{el}}$ (electrostatic). This separation has been discussed extensively in [43-47]:

$$
\Delta G=\Delta G_{\mathrm{nel}}+\Delta G_{\mathrm{el}}
$$

Thus, the free energy of binding $\Delta G$ can be written as a sum of two contributions: a nonelectrostatic contribution, $\Delta G_{\text {nel }}$, and an electrostatic one, $\Delta G_{\mathrm{el}}$, which implies

$$
K^{\mathrm{DNA} / \mathrm{AuNPs}}=K_{\mathrm{nel}} K_{\mathrm{el}} \text {. }
$$

In order to separate these contributions, we used Lippard's equation. According to Howe-Grant and Lippard [47], $\log K_{\mathrm{el}}$ is proportional to $-\log \left[\mathrm{Na}^{+}\right]$; that is,

$$
\log K^{\mathrm{DNA} / \mathrm{AuNPs}}=\log K_{\mathrm{nel}}-\beta \log \left[\mathrm{Na}^{+}\right] .
$$

The values of $\log K^{\text {AuNPs/DNA }}$ appearing in Table 1 are plotted in Figure 5. From the intercept, a value of $\log K_{\text {nel }}=4.98$ was found, which gives a value of $K_{\text {nel }}=9.5 \times 10^{4} \mathrm{M}^{-1}$. That is, taking into account the values of $K^{\mathrm{DNA} / \mathrm{AuNPs}}$ appearing in Table 1, it can be established that the nonelectrostatic component of the binding free energy is about $\sim 90 \%$ of the total free energy.

As mentioned previously, a second approach was used to obtain $K^{\mathrm{DNA} / A u N P s}$. This approach is based on the use of a fluorescent intercalator pyrene-1-carboxaldehyde [48]. This procedure has been used by one of the previous authors to measure the binding constant of surfactant to DNA [11]. 1$\mathrm{PyCHO}$ is a good probe for sensing polarity changes. This circumstance arises from the existence of two excited states that are close in energy: a fluorescent state and a "dark" state whose relative populations depend on the medium polarity. As a matter of fact, in the presence of DNA, we observed a diminution in the fluorescent intensity of 1-PyCHO $[10,49]$. The magnitude of these changes in the intensity depends also on the association degree of the gold nanoparticle with 


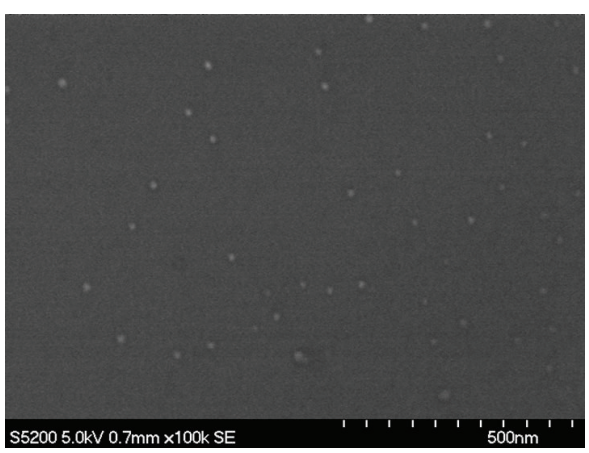

(a)

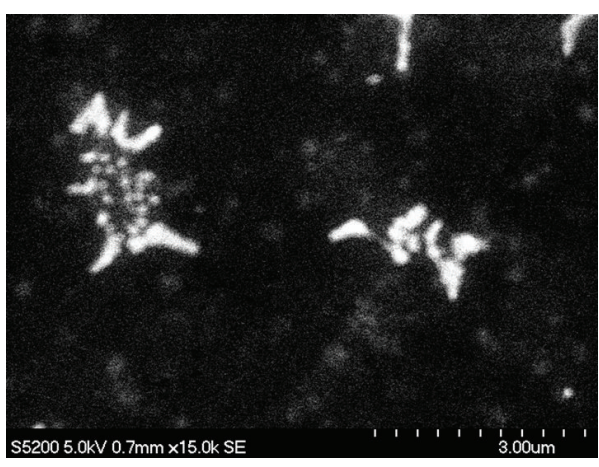

(c)

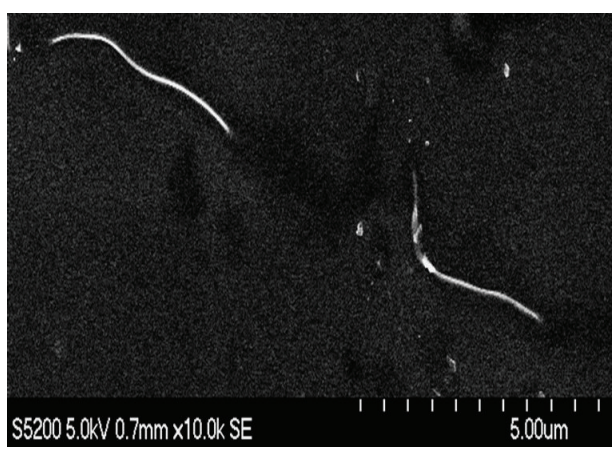

(b)

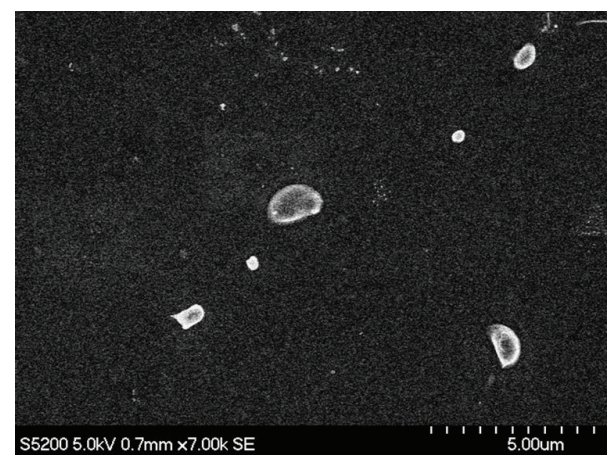

(d)

FIGURE 4: SEM images of CT-DNA at different concentrations of AuNPs in the presence of $[\mathrm{NaCl}]=0.015 \mathrm{M}$. $(\mathrm{a})[\mathrm{AuNPs}]=1 \times 10^{-6} \mathrm{M}$; (b) $[\mathrm{DNA}]=2 \times 10^{-6} \mathrm{M}$; (c) $[\mathrm{DNA}]=2.5 \times 10^{-6}$, $[$ AuNPs $]=2.5 \times 10^{-7} \mathrm{M}$; (d) $[\mathrm{DNA}]=2 \times 10^{-6} \mathrm{M}$, $[$ AuNPs $]=1 \times 10^{-6} \mathrm{M}$.

TABLE 2: Solubilities $(S)$, equilibrium binding constants $\left(K^{1-\mathrm{PyCHO} / \mathrm{DNA}}\right)$, and the corrected free energy $\left(\Delta G^{\mathrm{CORR}}\right)$ corresponding to 1 $\mathrm{PyCHO} / \mathrm{DNA}$ interaction at different Au@tiopronin concentrations.

\begin{tabular}{lccc}
\hline $10^{-6}[$ AuNPs $] / \mathrm{M}$ & $\mathrm{S} / \mathrm{M}$ & $10^{-4} \mathrm{~K}^{\mathrm{1}-\mathrm{PyCHO} / \mathrm{DNA} / \mathrm{M}^{-1}}$ & $\left(\Delta G^{\mathrm{CORR}}\right) / \mathrm{kJmol}^{-1}$ \\
\hline 0.0 & $1.21 \times 10^{-6}$ & 78.0 & -27.91 \\
2.5 & $3.02 \times 10^{-6}$ & 77.0 & -25.59 \\
6.0 & $1.21 \times 10^{-5}$ & 58.1 & -21.47 \\
10.0 & $2.41 \times 10^{-5}$ & 49.8 & -19.39 \\
20.0 & $2.49 \times 10^{-5}$ & 46.0 & -19.11 \\
\hline
\end{tabular}

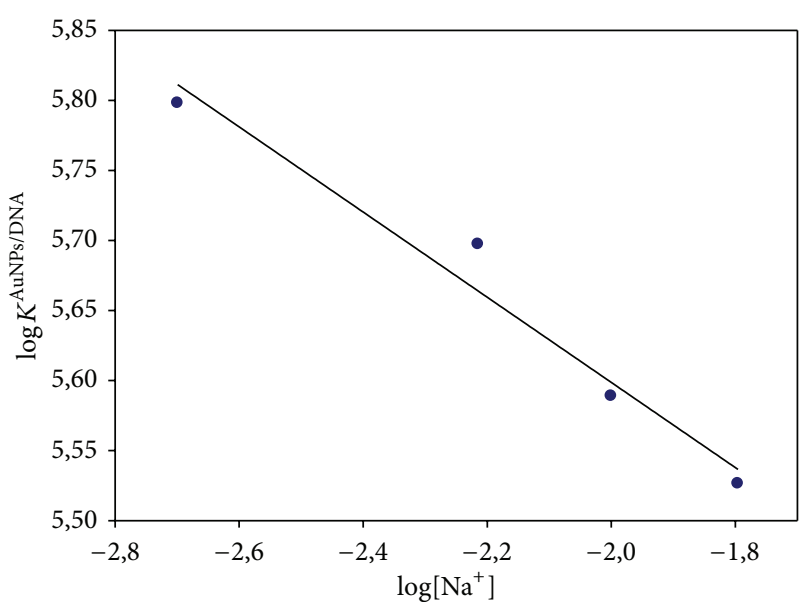

Figure 5: Plot of $\log K^{\mathrm{DNA} / \mathrm{AuNPs}}$ versus $\log \left[\mathrm{Na}^{+}\right]$(see (5)) for the DNA-AuNPs system.
DNA. This circumstance allows us to determine the binding constants of 1-PyCHO to DNA in the presence of different Au@tiopronin nanoparticles concentrations by using the Hildebrand-Benesi equation [50].

We performed experiments in which the fluorescence emission of 1-PyCHO was measured in the presence of a fixed concentration of Au@tiopronin and variable DNA concentrations. A typical example of binding isotherm obtained from these titrations is given in Figure 6, and plot shows that the binding saturation has been attained at $1.5 \times 10^{-4} \mathrm{M}$ of DNA. Besides, as the AuNPs, concentration increases in each titration, the amount of DNA needed to attain saturation increases. The values of the binding constants of 1-PyCHO/DNA are given in Table 2.

As can be seen, these binding constants depend on the nanoparticle concentration, that is, on the proportion of DNA free and bound to the Au@tiopronin nanoparticles (see (1)). From these values of $K^{1-\mathrm{PYCHO} / \mathrm{DNA}}$, those of 


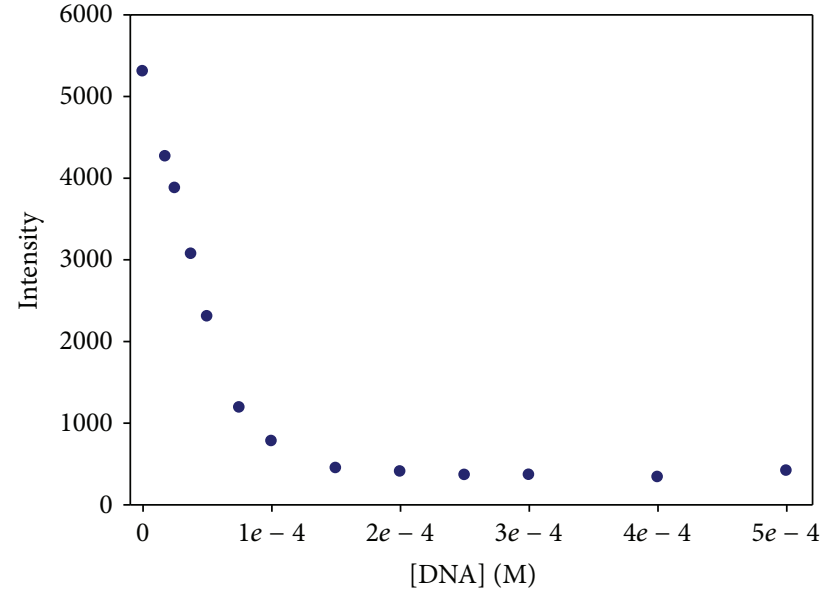

(a)

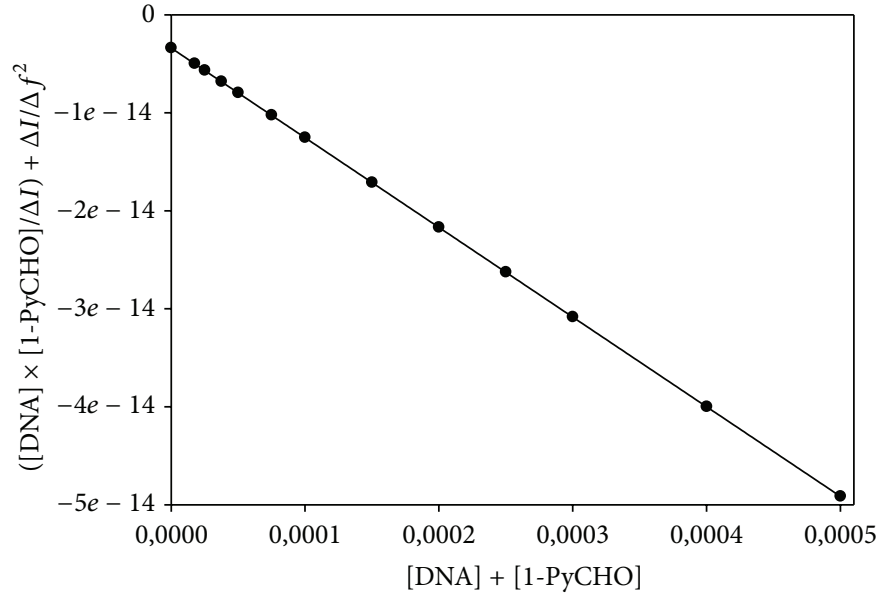

(b)

FIGURE 6: (a) Fluorescence titration $\left(\lambda_{\mathrm{em}}=458 \mathrm{~nm}\right)$ of 1-PyCHO with DNA in the presence of Au@tiopronin nanoparticles. ([1-PyCHO] = $5 \times 10^{-7} \mathrm{M}$; [AuNPs $]=6 \times 10^{-7} \mathrm{M}$; [DNA $]=0-5 \times 10^{-4} \mathrm{M}$, given in base pairs). (b) Fit of the data to Hildebrand-Benesi model.

$\Delta G=-R T \times \ln \left(K^{1-\mathrm{PYCHO} / \mathrm{DNA}}\right)$ were obtained. However, the values of $\Delta G$ represent the affinity of 1-PyCHO for the binding to DNA relative to the solutions where the free pyrene-1carboxaldehyde is present. Obviously, $\Delta G$ cannot be compared directly because these solutions are different. However, solubility measurements in Table 2 allow us to compare $\Delta G$ once they have been corrected, taking into account the differences in free energy of the probe in the solutions due to the presence of tiopronin gold nanoparticles. Thus, if $S_{0}$ is the solubility in the absence of Au@tiopronin and $S$ in the presence of a given concentration of the nanoparticle, this free energy, $\Delta G$, is related to the activity coefficient of 1-PyCHO, and the latter to the solubility:

$$
\Delta G=R T \ln \gamma_{1-\mathrm{PyCHO}}=R T \ln \frac{S_{0}}{S} .
$$

In this way, the values of $\Delta G^{\mathrm{CORR}}$ appearing in Table 2 were obtained:

$$
\Delta G^{\mathrm{CORR}}=\Delta G-R T \ln \frac{S_{0}}{S} .
$$

It is interesting to note that Table 2 shows that the $\Delta G^{\text {CORR }}$ values increase when Au@tiopronin concentrations do so. According to this fact, it must be inferred that gold nanoparticles modify DNA upon binding. Au@tiopronin nanoparticles induce a change in the DNA/AuNPs complex that makes it less efficient than free DNA in order to bind 1PyCHO. The effect of gold nanoparticles on DNA/1-PyCHO system is to induce a structural change in the DNA, which will be the result of the structural modifications due to the gold core and the tiopronin tails of the nanoparticle. Therefore, two kinds of DNA will be in the solution, free and bound to Au@tiopronin, with different capacities to bind 1-PyCHO, in the sense that the corrected binding free energy of the dye will be different for each kind of DNA. It can be shown (see Supporting Information available online at http://dx.doi.org/10.1155/2014/143645) that the observed corrected free energies, $\Delta G^{\mathrm{CORR}}$, will be given by

$$
\begin{aligned}
& \Delta G^{\mathrm{CORR}} \\
& \quad=\frac{\Delta G_{1}^{\mathrm{CORR}}+\Delta G_{2}^{\mathrm{CORR}}\left(K_{2} / K_{1}\right) K^{\mathrm{DNA} / \mathrm{AuNPs}}[\text { AuNPs }]}{1+\left(1+K_{2}\right)\left(K^{\mathrm{DNA} / \text { AuNPs }} / K_{1}\right)[\text { AuNPs }]} .
\end{aligned}
$$

In this equation, $\Delta G_{1}^{\mathrm{CORR}}$ is the corrected free energy of binding of 1-PyCHO with free DNA, that is, to DNA without Au@tiopronin; meanwhile, $\Delta G_{2}^{\mathrm{CORR}}$ is the same but when the DNA is bound to the gold nanoparticles, AuNPs; $K_{1}$ is the equilibrium binding constant 1-PyCHO/DNA in the absence of Au@tiopronin and $K_{2}$ is the equilibrium binding constant 1-PyCHO/DNA in the saturation limit of AuNPs. Finally, $K^{\mathrm{DNA} / \mathrm{AuNPs}}$ is the equilibrium constant for the binding of the Au@tiopronin with DNA (see Scheme 1). In other words, changes in $\Delta G^{\mathrm{CORR}}$ can be interpreted using a two-state model of the DNA/AuNPs binding.

Figure 7 corresponds to the fit of data in Table 2 to (8). A value of $K^{\text {DNA/AuNPs }}=5.9 \times 10^{5}\left(\mathrm{M}^{-1}\right)$ was obtained, with $K_{2}=2.2 \times 10^{4}$ and $K_{1}=8.1 \times 10^{4} \mathrm{M}^{-1}$. The agreement of this value with the corresponding one obtained through $C D$ measurements supports our simpler methodology based on the two-state model.

\section{Conclusions}

The interaction of gold nanoparticles capped with tiopronin of $1.4 \mathrm{~nm}$ core size with DNA was investigated by using different techniques: CD, SEM, UV-vis, and fluorescence spectroscopy. A simple methodology to quantify the free energy of AuNPs/DNA binding has been proposed based on CD spectral change during AuNPs titration. A complementary study using pyrene-1-carboxaldehyde as a fluorescence probe supports the thermodynamic results obtained. Our results 


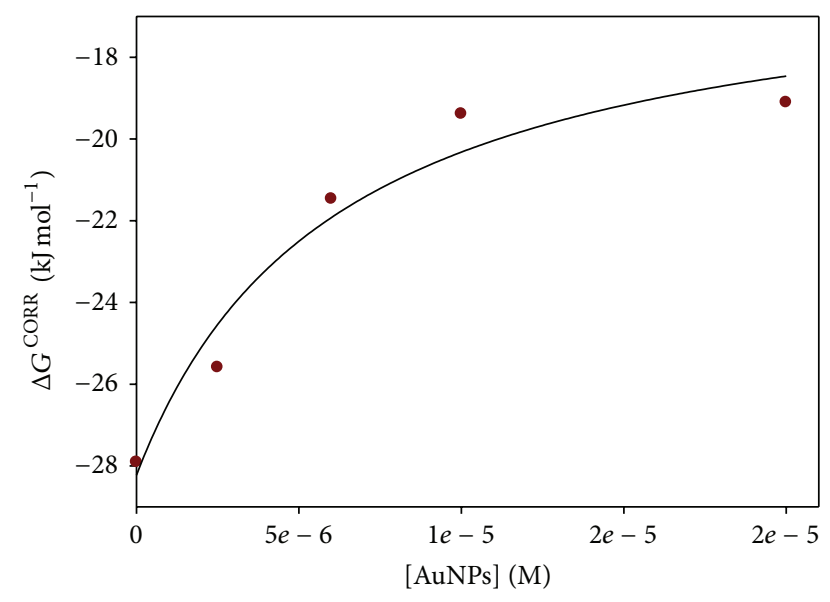

Figure 7: Corrected free energy of 1-PyCHO/AuNPs interaction, $\Delta G^{\mathrm{CORR}}$, versus [AuNPs], best fit to (8).

in the presence of different sodium chloride concentrations revealed that the AuNPs/DNA binding is fundamentally of nonelectrostatic character. The results provide an alternative method to quantify binding free energy of AuNPs/DNA-like systems when small changes in the titration are registered using conventional spectroscopic techniques.

\section{Conflict of Interests}

The authors declare that there is no conflict of interests regarding the publication of this paper.

\section{Acknowledgments}

This work was financed by the DIGYT (CTQ2008-0008/ BQU) and the Council of Education and Science of the Junta de Andalucía.

\section{References}

[1] M. Scott Vandiver, E. Page Bridges, R. L. Koon et al., "Effect of ancillary ligands on the DNA interaction of $\left[\mathrm{Cr}(\text { diimine })_{3}\right]^{3+}$ complexes containing the intercalating dipyridophenazine ligand," Inorganic Chemistry, vol. 49, no. 3, pp. 839-848, 2010.

[2] M. C. DeRosa and R. J. Crutchley, "Photosensitized singlet oxygen and its applications," Coordination Chemistry Reviews, vol. 233-234, pp. 351-371, 2002.

[3] J. C. Genereux and J. K. Barton, "Mechanisms for DNA charge transport," Chemical Reviews, vol. 110, no. 3, pp. 1642-1662, 2010.

[4] M. Akbulut, A. R. G. Alig, Y. Min et al., "Forces between surfaces across nanoparticle solutions: role of size, shape, and concentration," Langmuir, vol. 23, no. 7, pp. 3961-3969, 2007.

[5] N. L. Rosi and C. A. Mirkin, "Nanostructures in biodiagnostics," Chemical Reviews, vol. 105, no. 4, pp. 1547-1562, 2005.

[6] E. Katz and I. Willner, "Integrated nanoparticle-biomolecule hybrid systems: synthesis, properties, and applications," Angewandte Chemie, vol. 116, pp. 6166-6235, 2004.

[7] M. T. Castañeda, S. Alegret, and A. Merkoçi, "Electrochemical sensing of DNA using gold nanoparticles," Electroanalysis, vol. 19, no. 7-8, pp. 743-753, 2007.
[8] R. Sánchez, M. Villar, A. Guiraum, and R. Prado-Gotor, "Restricted geometry conditions promoted by $\mathrm{AlOOH}$ nanoparticles: variable strength and character of $\mathrm{AlOOH}$ cluster/charged ligand interactions as a consequence of changes in the solvent," Journal of Physical Chemistry C, vol. 112, no. 25, pp. 9240-9246, 2008.

[9] E. Grueso, G. López-Pérez, M. Castellano, and R. PradoGotor, "Thermodynamic and structural study of phenanthroline derivative ruthenium complex/DNA interactions: probing partial intercalation and binding properties," Journal of Inorganic Biochemistry, vol. 106, no. 1, pp. 1-9, 2012.

[10] E. Grueso, F. Sánchez, V. I. Martin, E. García-Fernández, and R. Prado-Gotor, "Quantification of salts and cosolvents-DNA interactions in terms of free energies: a study using the pyren1-carboxyaldehyde as fluorescent probe," Chemical Physics, vol. 352, no. 1-3, pp. 306-310, 2008.

[11] E. Grueso and F. Sánchez, "DNA-surfactant interactions: a procedure for determination group contributions," Journal of Physical Chemistry B, vol. 112, no. 3, pp. 698-702, 2008.

[12] F. Secco, M. Venturini, T. Biver, F. Sánchez, R. Prado-Gotor, and E. Grueso, "Solvent effects on the kinetics of the interaction of 1- pyrenecarboxaldehyde with calf thymus DNA," Journal of Physical Chemistry B, vol. 114, no. 13, pp. 4686-4691, 2010.

[13] R. Prado-Gotor and E. Grueso, "A kinetic study of the interaction of DNA with gold nanoparticles: mechanistic aspects of the interaction," Physical Chemistry Chemical Physics, vol. 13, no. 4, pp. 1479-1489, 2011.

[14] T. Lopès-Costa, F. Sánchez, and P. Lopez-Cornejo, "Cooperative and noncooperative binding of ${ }^{*} \mathrm{Ru}(\mathrm{bpy})_{3}^{2+}$ to $\mathrm{DNA}$ and $\mathrm{SB}_{4.5} \mathrm{G}$ dendrimers," Journal of Physical Chemistry B, vol. 113, no. 28, pp. 9373-9378, 2009.

[15] R. de la Vega, P. Pérez, R. Prado-Gotor, and F. Sánchez, "DNA interactions with small solutes: change in the character of the binding of $\left[\mathrm{Ru}\left(\mathrm{NH}_{3}\right)_{5} \mathrm{pz}\right]^{2+}$ to DNA as a consequence of changes in the solvent," Chemical Physics, vol. 297, no. 1-3, pp. 163-169, 2004.

[16] P. Perez-Tejeda, R. Prado-Gotor, and E. M. Grueso, "Electrochemiluminescence of the $\left[\mathrm{Ru}(\mathrm{bpy})_{3}\right]^{2+}$ complex: the coreactant effect of PAMAM dendrimers in aqueous medium," Inorganic Chemistry, vol. 51, pp. 10825-10831, 2012.

[17] J. Zhou, J. Ralston, R. Sedev, and D. A. Beattie, "Functionalized gold nanoparticles: synthesis, structure and colloid stability," Journal of Colloid and Interface Science, vol. 331, no. 2, pp. 251262, 2009.

[18] P. V. Baptista, M. Koziol-Montewka, J. Paluch-Oles, G. Doria, and R. Franco, "Gold-nanoparticle-probe-based assay for rapid and direct detection of Mycobacterium tuberculosis DNA in clinical samples," Clinical Chemistry, vol. 52, no. 7, pp. 14331434, 2006.

[19] D. G. Georganopoulou, L. Chang, J.-M. Nam et al., 'Nanoparticle-based detection in cerebral spinal fluid of a soluble pathogenic biomarker for Alzheimer's disease," Proceedings of the National Academy of Sciences of the United States of America, vol. 102, no. 7, pp. 2273-2276, 2005.

[20] G. Han, P. Ghosh, M. De, and V. M. Rotello, "Drug and gene delivery using gold nanoparticles," Nanobiotechnology, vol. 3, no. 1, pp. 40-45, 2007.

[21] Y. Zhang, K. Zhang, and H. Ma, "Electrochemical DNA biosensors based on gold nanoparticles/cysteamine/poly(glutamic acid) modified electrode," American Journal of Biomedical Sciences, vol. 1, no. 2, pp. 115-125, 2009. 
[22] W. S. Seung, C. S. Woo, K. A. Ra, C. Seung-Woo, K. Dong-Ik, and U. Soong, "Novel stem-loop RNA and drug-bearing DNA hybrid nanostructures specific to LNCaP prostate carcinoma," Biomaterials Science, vol. 2, pp. 76-83, 2013.

[23] D. E. Cliffel, F. P. Zamborini, S. M. Gross, and R. W. Murray, "Mercaptoammonium-monolayer-protected, water-soluble gold, silver, and palladium clusters," Langmuir, vol. 16, no. 25, pp. 9699-9702, 2000.

[24] H. Yao, S. S. Ng, W. O. Tucker et al., "The gene transfection efficiency of a folate-PEI600-cyclodextrin nanopolymer," Biomaterials, vol. 30, no. 29, pp. 5793-5803, 2009.

[25] A. K. R. Lytton-Jean and C. A. Mirkin, "A thermodynamic investigation into the binding properties of DNA functionalized gold nanoparticle probes and molecular fluorophore probes," Journal of the American Chemical Society, vol. 127, no. 37, pp. 12754-12755, 2005.

[26] C. S. Thaxton, D. G. Georganopoulou, and C. A. Mirkin, "Gold nanoparticle probes for the detection of nucleic acid targets," Clinica Chimica Acta, vol. 363, no. 1-2, pp. 120-126, 2006.

[27] X. Wang, O. Ramström, and M. Yan, "Glyconanomaterials: synthesis, characterization, and ligand presentation," Advanced Materials, vol. 22, no. 17, pp. 1946-1953, 2010.

[28] C. M. Goodman, N. S. Chari, G. Han, R. Hong, P. Ghosh, and V. M. Rotello, "DNA-binding by functionalized gold nanoparticles: mechanism and structural requirements," Chemical Biology and Drug Design, vol. 67, no. 4, pp. 297-304, 2006.

[29] G. Wang, J. Zhang, and R. W. Murray, "DNA binding of an ethidium intercalator attached to a monolayer-protected gold cluster," Analytical Chemistry, vol. 74, no. 17, pp. 4320-4327, 2002.

[30] A. A. Zinchenko, K. Yoshikawa, and D. Baigl, "Compaction of single-chain DNA by histone-inspired nanoparticles," Physical Review Letters, vol. 95, no. 22, Article ID 228101, 4 pages, 2005.

[31] M. Rahban, A. Divsalar, A. A. Saboury, and A. Golestani, "Nanotoxicity and spectroscopy studies of silver nanoparticle: calf thymus DNA and K562 as targets," Journal of Physical Chemistry C, vol. 114, no. 13, pp. 5798-5803, 2010.

[32] Z. Atay, T. Biver, A. Corti et al., "Non-covalent interactions of cadmium sulphide and gold nanoparticles with DNA," Journal of Nanoparticle Research, vol. 12, no. 6, pp. 2241-2253, 2010.

[33] P. S. Ghosh, G. Han, B. Erdogan, O. Rosado, S. A. Krovi, and V. M. Rotello, "Nanoparticles featuring amino acid-functionalized side chains as DNA receptors," Chemical Biology and Drug Design, vol. 70, no. 1, pp. 13-18, 2007.

[34] G. Felsenfeld and S. Z. Hirschman, "A neighbor-interaction analysis of the hypochromism and spectra of DNA," Journal of Molecular Biology, vol. 13, no. 2, pp. 407-427, 1965.

[35] A. C. Templeton, S. Chen, S. M. Gross, and R. W. Murray, "Water-soluble, isolable gold clusters protected by tiopronin and coenzyme a monolayers," Langmuir, vol. 15, no. 1, pp. 66-76, 1999.

[36] J. M. de la Fuente, C. C. Berry, M. O. Riehle, and A. S. G. Curtis, "Nanoparticle targeting at cells," Langmuir, vol. 22, no. 7, pp. 3286-3293, 2006.

[37] T. Huang and R. W. Murray, "Visible luminescence of watersoluble monolayer-protected gold clusters," Journal of Physical Chemistry B, vol. 105, no. 50, pp. 12498-12502, 2001.

[38] M. B. Mohamed, V. Volkov, S. Link, and M. A. El-Sayed, “The lightning gold nanorods: fluorescence enhancement of over a million compared to the gold metal," Chemical Physics Letters, vol. 317 , no. 6 , pp. 517-523, 2000.
[39] S. Link and M. A. El-Sayed, "Shape and size dependence of radiative, non-radiative and photothermal properties of gold nanocrystals," International Reviews in Physical Chemistry, vol. 19, no. 3, pp. 409-453, 2000.

[40] S. Neidle, Nucleic Acid Structure and Recognition, Oxford University Press, New York, NY, USA, 2002.

[41] M. F. Maestre and J. C. Wang, "Circular dichroism of superhelical DNA," Biopolymers, vol. 10, no. 6, pp. 1021-1030, 1971.

[42] B. Alberts, A. Johnson, J. Lewis, M. Raff, K. Roberts, and P. Walter, Molecular Biology of the Cell, Galland, New York, NY, USA, 4th edition, 2002.

[43] C. Dolcet and E. Rodenas, "An electrostatic approach to negatively charged substrate reactions with hydroxide ion in cationic CTAB micelles," Canadian Journal of Chemistry, vol. 68, pp. 932-938, 1990.

[44] F. Ortega and E. Rodenas, "An electrostatic approach for explaining the kinetic results in the reactive counterion surfactants CTAOH and CTACN," Journal of Physical Chemistry, vol. 91, no. 4, pp. 837-840, 1987.

[45] C. A. Bunton and J. R. Moffatt, "Ionic competition in micellar reactions: a quantitative treatment," Journal of Physical Chemistry, vol. 90, no. 4, pp. 538-541, 1986.

[46] H. A. Al-Lohedan, "Quantitative treatment of micellar effects upon nucleophilic substitution," Journal of the Chemical Society, Perkin Transactions 2, no. 8, pp. 1707-1713, 1995.

[47] T. G. Dewey and D. H. Turner, "Laser temperature-jump study of stacking in adenylic acid polymers," Biochemistry, vol. 18, no. 26, pp. 5757-5762, 1979.

[48] E. Grueso and R. Prado-Gotor, "Thermodynamic and structural study of pyrene-1-carboxaldehyde/DNA interactions by molecular spectroscopy: probing intercalation and binding properties," Chemical Physics, vol. 373, no. 3, pp. 186-192, 2010.

[49] M. Nakamura, Y. Fukunaga, K. Sasa et al., "Pyrene is highly emissive when attached to the RNA duplex but not to the DNA duplex: the structural basis of this difference," Nucleic Acids Research, vol. 33, no. 18, pp. 5887-5895, 2005.

[50] H. A. Benesi and J. H. Hildebrand, "A spectrophotometric investigation of the interaction of iodine with aromatic hydrocarbons," Journal of the American Chemical Society, vol. 71, no. 8, pp. 2703-2707, 1949. 

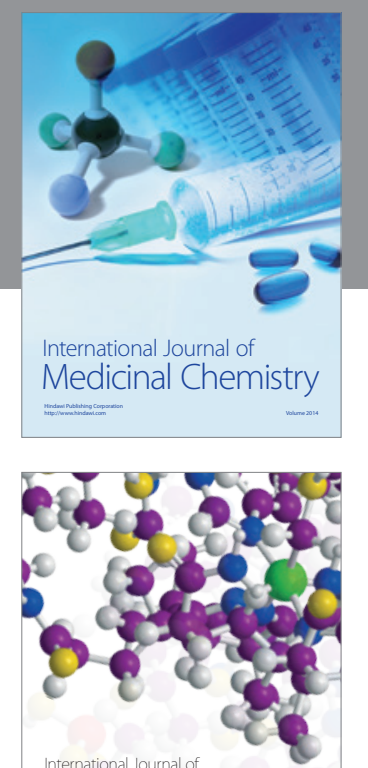

\section{Carbohydrate} Chemistry

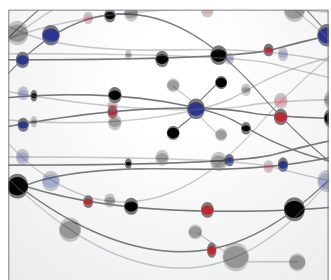

The Scientific World Journal
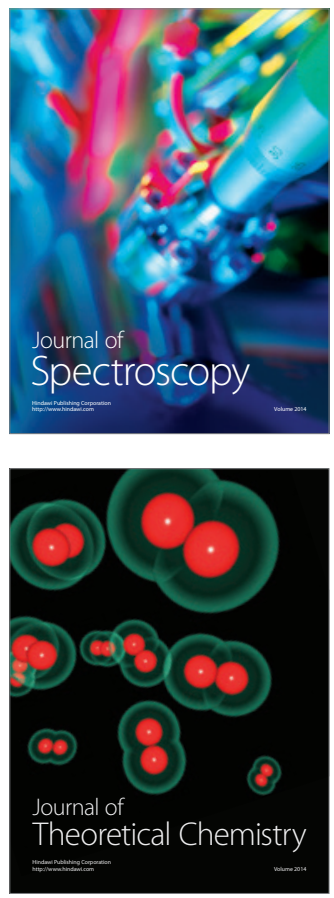
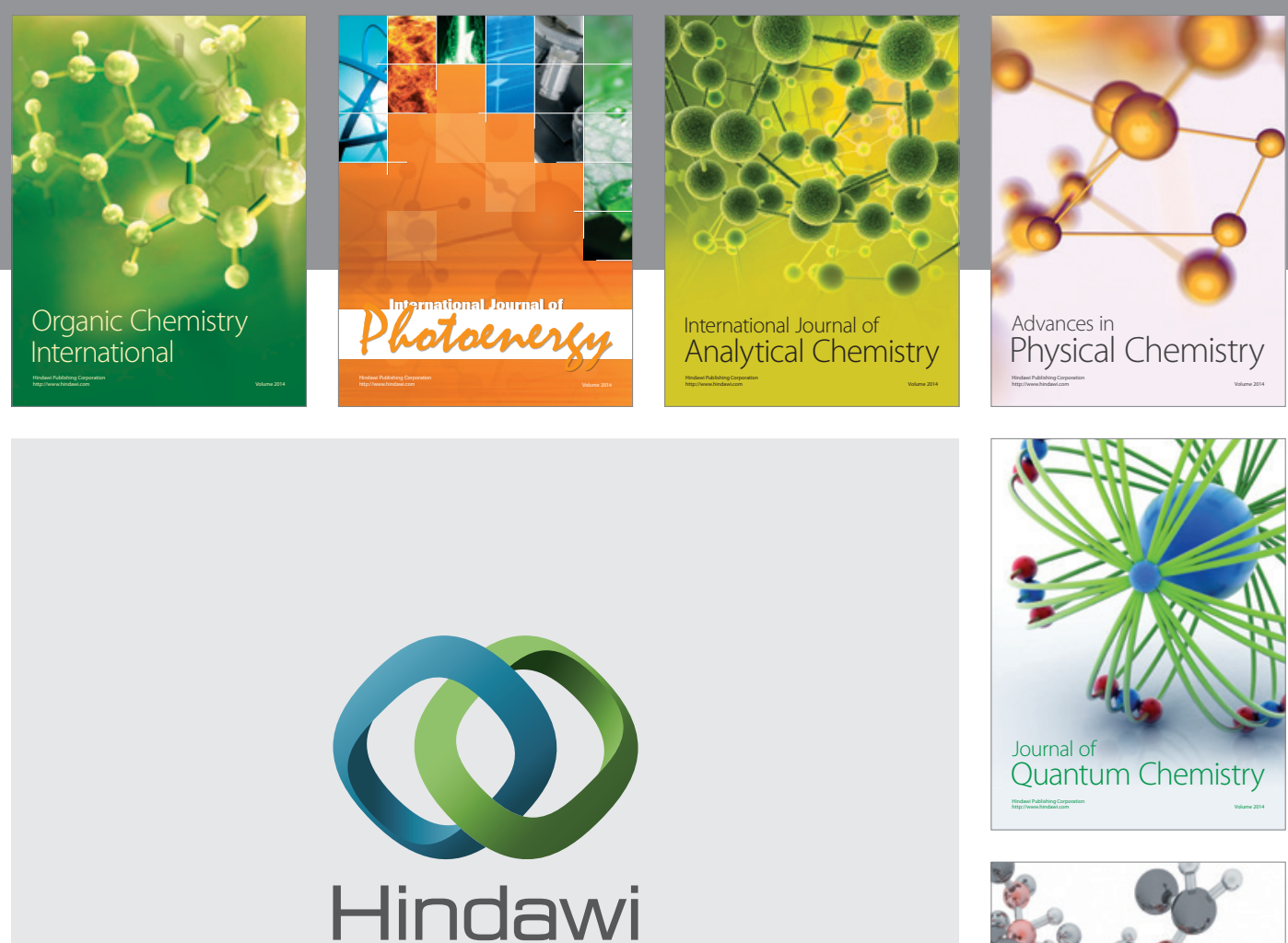

Submit your manuscripts at

http://www.hindawi.com

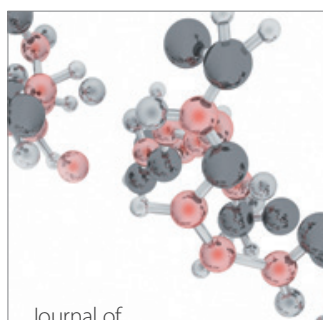

Analytical Methods

in Chemistry

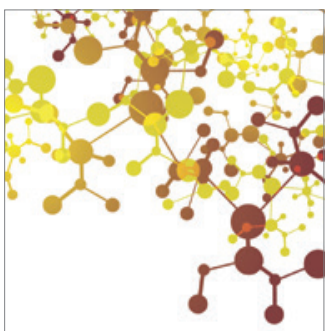

Journal of

Applied Chemistry

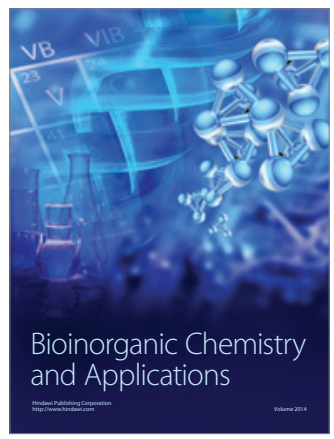

Inorganic Chemistry
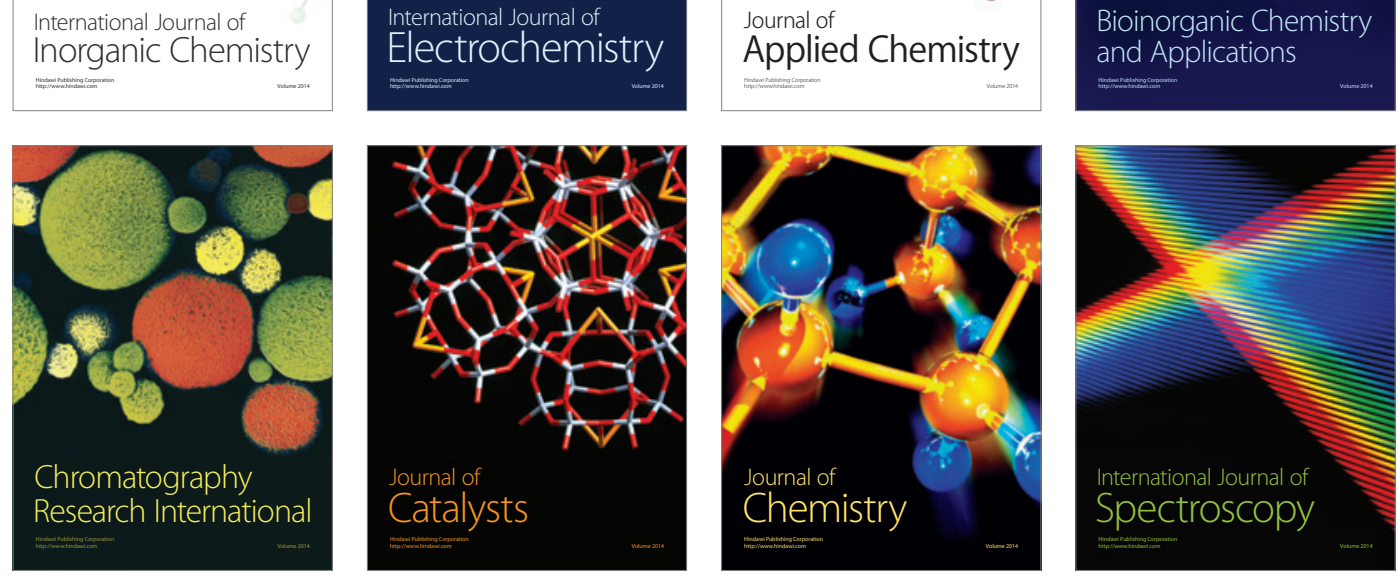